\title{
EVALUASI EFEKTIVITAS, KONTRIBUSI DAN POTENSI PENERIMAAN PAJAK HOTEL TERHADAP PENDAPATAN ASLI DAERAH KABUPATEN MINAHASA UTARA
}

\author{
Pongtuluran Andri Christian ${ }^{1}$, Jullie J. Sondakh ${ }^{2}$, Novi Burdiarso ${ }^{3}$ \\ 1,2,3 Jurusan Akuntansi, Fakultas Ekonomi dan Bisnis, Universitas Sam Ratulangi, Jl. Kampus Bahu, Manado, \\ 95115, Indonesia
}

e-mail: andripongtuluran46@gmail.com

\begin{abstract}
Regional development needs to be run or developed as an important effort to realize broad, real and responsible autonomy. Officially, Regional Autonomy is effective in Indonesia since January 1, 2001, so that regions are required to seek alternative sources of revenue that can be used to finance regional expenditures or expenditures. Since the enactment of Regional Autonomy, local governments are granted the right, authority and obligation to manage and manage their own affairs government and local communities within the system of the Unitary State of the Republic of Indonesia. Implementation of broad autonomy, real and responsible required the ability of regions to explore their own financial resources supported by the financial balance between the Central Government and Local Government.This study aims to determine the evaluation of the effectiveness, contribution and potential tax revenues to revenue native regency north minahasa. Data analysis used qualitative descriptive data. The results of this study the authors found that the effectiveness of income changed so as to the contribution and potential of hotel tax revenues. Based on this research, it can be concluded that the company needs to increase the effectiveness of contribution and the potential of tax revenue to increase local revenue. That way the authors can provide suggestions that the government continues to improve its performance so that the professionalism of work continues to improve and the level of effectiveness that has been good to continue to consistently increase.
\end{abstract}

Keywords: evektifitas, contribution, potential tax revenue, local revenue

\section{PENDAHULUAN}

Pembangunan daerah perlu dijalankan atau dikembangkan sebagai salah satu upaya penting untuk mewujudkan otonomi yang luas, nyata dan bertanggung jawab. Secara resmi Otonomi Daerah berlaku di Indonesia sejak 1 Januari 2001, sehingga daerah dituntut mencari berbaga alternatif sumber penerimaan yang dapat digunakan untuk membiayai pengeluaran atau belanja daerah. Pemberian kewenangan kepada daerah untuk memungut pajak dan retribusi daerah diperlukan adanya landasan hukum berupa Undang-Undang. Sebagai landasan hukum yang merupakan dasar hukum pungutan Pajak Daerah dan Retribusi Daerah yaitu Undang-Undang Nomor 18 Tahun 1997 tentang Pajak Daerah dan Retribusi Daerah sebagaimana telah diubah terakhir dengan Undang-Undang nomor 28 Tahun 2009 yang berlaku sejak 1 Januari 2010.

Sejak berlakunya Otonomi Daerah, pemerintah daerah diberikan hak, kewenangan dan kewajiban untuk mengatur dan mengurus sendiri urusan pemerintahan dan masyarakat setempat dalam sistem Negara Kesatuan Republik Indonesia. Penyelenggaraan otonomi yang luas, nyata dan bertanggung jawab diperlukan kemampuan daerah untuk menggali sumber keuangan sendiri yang didukung oleh perimbangan keuangan antara Pemerintah Pusat dan Pemerintah Daerah. Pemerintah daerah tidak hanya dituntut untuk mampu menyelenggarakan pemerintahan, pembangunan dan pelayanan akan tetapi secara finansial mampu untuk membiayai kebutuhannya. Untuk merealisasikan Pelaksanaan Otonomi Daerah maka sumber 
pembiayaan pemerintah daerah tergantung dari peranan Pendapatan Asli Daerah (PAD). Hal ini diharapkan dan diupayakan dapat menjadi penyangga utama dalam membiayai kegiatan pembangunan di daerah. Oleh karena itu Pemerintah Daerah harus dapat mengupayakan peningkatan penerimaan yang berasal dari daerah sendiri sehingga akan memperbesar tersedianya keuangan daerah yang dapat digunakan untuk berbagai kegiatan pembangunan. Dengan ini akan semakin memperbesar keleluasaan daerah untuk mengarahkan penggunaan keuangan daerah sesuai dengan rencana dan kebutuhan daerah yang bersangkutan. Tujuan dari penelitian ini adalah untuk mengevaluasi:

1. Efektivitas pajak hotel terhadap Pendapatan Asli Daerah Kabupaten Minahasa Utara.

2. Kontribusi pajak hotel terhadap Pendapatan Asli Daerah Kabupaten Minahasa Utara.

3. Potensi penerimaan pajak hotel di Kabupaten Minahasa Utara.

\section{TINJAUAN PUSTAKA \\ Pengertian Akuntansi}

Akuntansi adalah proses pencatatan, penggolongan, peringkasan dan penyajian dengan cara-cara tertentu terhadap transkasi keuangan yang terjadi dalam perusahaan atau organisasi lainnya serta interprestasinya terhadap hasilnya. Akuntansi adalah seni pencatatan, pengklasifikasikan dan peringkasan mengenai data keuangan, ttransaksi dan kejadian yang menjadi bagian dari karakteristik keuangan serta menginterpretasikannya (Francis, 2013). Akuntansi sering disebut sebagai bahasa bisnis atau sering disebut sebagai bahasa dari keputusan bisnis, dan akuntansi pada dasarnya akan menghasilkan informasi dari sebuah sistem akuntansi yang ada didalam sebuah entitas atau organisasi bisnis yang disebut dengan informasi akuntani yang akan dimanfaatkan oleh pengguna seperti masyarakat intelektual (termasuk didalamnya mahasiswa dan peneliti)dan para pengambil keputusan bisnis dalam organisasi. (Lamia, 2015:3).

\section{Pengertian Pajak}

Pajak adalah bantuan, baik secara langsung maupun secara tidak langsung yang dipaksakan oleh kekuasaan public dari penduduk atau dari barang, untuk menutupi belanja pemerintah. Artinya pajak merupakan suatu pemungutan dari masyarakat yang berguna untuk kepentingan Negara. (Sondakh, Ibrahim \& Wangkar, 2016:3). Waluyo (2011:2), pajak adalah iuran kepada negara (yang dapat dipaksakan) yang terutang oleh yang wajib membayarnya menurut peraturan-peraturan, dengan tidak mendapat prestasi kembali, yang langsung dapat ditunjuk, dan yang gunanya adalah untuk membiayai pengeluaran-pengeluaran umum berhubung dengan tugas negara yang menyelenggarakan pemerintahan.

\section{Pengertian Pajak Hotel}

Berdasarkan Undang-Undang Nomor 28 Tahun 2009 tentang Pajak Daerah dan Retribusi Daerah, Pajak Hotel adalah pajak atas pelayanan yang disediakan oleh hotel. Hotel adalah bangunan yang khusus disediakan bagi orang untuk dapat menginap/beristirahat, memperoleh pelayanan, dan atau fasilitas lainnya dengan dipungut bayaran, termasuk bangunan lainnya yang menyatu, yang dikelola dan dimiliki oleh pihak yang sama, kecuali pertokoan. (Khotimah, 2014:5)

\section{Pendapatan Asli Daerah}

Pendapatan Daerah adalah semua hak daerah yang diakui sebagai nilai kekayaan bersih dalam periode anggaran tertentu. Sesuai dengan Undang-Undang Nomor 32 Tahun 2004 Tentang Pemerintahan daerah, bahwa pendapatan daerah berasal dari penerimaan dari dana perimbangan pusat dan daerah, juga yang berasal dari daerah itu sendiri yaitu pendapatan asli daerah serta lain-lain pendapatan yang sah. Undang-Undang Nomor 28 Tahun 2009 tentang Pajak Daerah dan Retribusi Daerah, yaitu Pendapatan Asli Daerah adalah sumber keuangan daerah yang digali dari wilayah Daerah yang bersangkutan yang 
terdiri dari hasil Pajak Daerah, hasil Retribusi Daerah, hasil pengelolaan kekayaan Daerah yang dipisahkan dan lain-lain Pendapatan Asli Daerah yang sah.

\section{Penelitian Terdahlu}

1. Rezlianti Kobandaha (2016), meneliti tentang Analisis Efektivitas, Kontribusi dan Potensi Pajak Reklame dan Pajak Hotel Terhadap Pendapatan Asli Daerah Kota Kotamobagu. Untuk mengetahui tingkat efektivitas, seberapa besar kontribusi, dan seberapa besar potensi penerimaan pajak reklame dan pajak hotel terhadap pendapatan asli daerah yg dimiliki Kota Kotamobagu, hasil penelitian menunjukkan Dalam tahun anggaran 20122015, pajak reklame sangat efektif sedangkan pajak hotel efektif. Kontribusi pajak reklame rata-rata sebesar $1,75 \%$, sedangkan pajak hotel $1,25 \%$. Potensi penerimaan keduanya dalam tahun 2016 meningkat.

2. Ronald Bua Toding (2016), Analisis Potensi dan Efektivitas Pemungutan Pajak Hotel Dalam Meningkatkan Pendapatan Asli Daerah Kota Palangka Raya. Tujuan penelitian Untuk mengetahui potensi Pajak Hotel yang dimiliki oleh Kota Palangka Raya dan mengetahui Efektivitas Pemungutan Pajak di kota Palangka Raya. Hasil penelitian menunjukkan Potensi Pajak Hotel ditahun 2011-2014 mengalami peningkatan, namun selama periode tahun 2011 hingga tahun 2014, target realisasi penerimaan Pajak Hotel belum pernah melampaui Potensi Riil penerimaan Pajak Hotel. Efektivitas pajak Hotel di Kota Palangka Raya selama periode penelitian termasuk efektif.

3. Alfan A. Lamia (2015), meneliti tentang Analisis Efektivitas dan Kontribusi Pemungutan Pajak Restoran, Pajak Reklame, dan Pajak Penerangan Jalan Pada Pendapatan Asli Daerah Kabupaten Minahasa Utara. Tujuan penelitian Untuk mengetahui tingkat efektivitas peneriamaan dan seberapa besar Kontribusi pajak restoran, pajak reklame, dan pajak penerangan jalan terhadap pendapatan asli daerah dari tahun 2010-2014. Hasil dari penelitian ini menunjukkan Tingkat efektivitas penerimaan pajak restoran, reklame dan penerangan jalan dalam periode 2010-2014 sangat bervariasi, namun secara keseluruhan sudah efektif. Kontribusi terhadap PAD baik dan realisasi penerimaan PAD dalam lima tahun terakhir mengalami peningkatan setiap tahunnya.

\section{METODE PENELITIAN}

3.1. Jenis dan sumber data

Penelitian ini termasuk pada jenis penelitian deskriptif. Mendefinisikan bahwa penelitian deskriptf merupakan jenis penelitian yang tujuannya untuk menyiapkan gambaran lengkap mengenai setting sosial atau hubungan angtara fenomena yang diuji. Metode deskriptif yaitu metode yang digunakan untuk menggambarkan atau menganalisis suatu hasil penelitian tetapi tidak digunakan untuk menarik kesimpulan yang lebih luas. (Sugiyono 2011:21)

\subsection{Sampel dan teknik pengambilan sampel}

Jenis Penelitian ini menggunakan penelitian deskriptif kualitatif. Penelitian deskriptif kualitatif merupakan jenis penelitian yang tujuannya untuk menyiapkan gambaran lengkap mengennai setting social atau hubungan antara fenomena yang diuji. Metode deskriptif yaitu metode yang digunakan untuk menggambarkan atau menganalisis suatu hasil penelitian tetapi tidak digunakan untuk menggunakan kesimpulan yang lebih luas. (Sugiyono 2011:11)

\subsection{Metode analisis}

Metode pengumpulan data yang di gunakan dalam penelitian ini adalah adalah wawancara, observasi, pengumpulan dokumen, dan studi kepustakaan. 


\section{HASIL ANALISIS DAN PEMBAHASAN \\ 4.1. Hasil analisis \\ Tabel 1.1 Realisasi Penerimaan Pajak Hotel Kabupaten Minahasa Utara Tahun 2011-2015}

\begin{tabular}{ccccc}
\hline No & Tahun & Target Pajak Hotel (Rp) & Realisasi Pajak Hotel (Rp) & Keterangan \\
\hline $\mathbf{1}$ & 2011 & 380.000 .000 & 449.277 .596 & Naik \\
$\mathbf{2}$ & 2012 & 867.180 .000 & 593.931 .004 & Turun \\
$\mathbf{3}$ & 2013 & 487.000 .000 & 549.862 .872 & Naik \\
$\mathbf{4}$ & 2014 & 805.000 .000 & 746.875 .269 & Turun \\
$\mathbf{5}$ & 2015 & 1.681 .078 .927 & 1.700 .057 .510 & Naik \\
\hline
\end{tabular}

Sumber: Dinas Pendapatan Daerah Kabupaten Minahasa Utara, 2017

Berdasarkan Tabel 1.1 dapat dilihat bahwa realisasi penerimaan pajak hotel di Kabupaten Minahasa Utara tahun anggaran 2011-2015. Pada tahun 2011 target pendapatan sebesar Rp 380.000.000,00 dan realisasi sebesar Rp 449. 277.596,00. Pada tahun 2012 target pendapatan sebesar Rp 867.180.000,00 dan realisasi sebesar Rp 593.931.004,00. Pada tahun 2013 target pendapatan sebesar Rp 487.000.000,00 dan realisasi sebesar Rp 549.862.872,00. Pada tahun 2014 target pendapatan sebesar Rp 805.000.000,00 dan realisasi sebesar Rp 746.875. 269,00, dan pada tahun 2015 target penerimaan sebesar Rp 1.681.078.927,00 dan realisasi penerimaan sebesar Rp 1.700.057.510,00.

Tabel 1.1 Realisasi Penerimaan Pajak Hotel Kabupaten Minahasa Utara Tahun 20112015

\begin{tabular}{ccccc}
\hline No & Tahun & Target Pajak Hotel (Rp) & Realisasi Pajak Hotel (Rp) & Keterangan \\
\hline $\mathbf{1}$ & 2011 & 380.000 .000 & 449.277 .596 & Naik \\
$\mathbf{2}$ & 2012 & 867.180 .000 & 593.931 .004 & Turun \\
$\mathbf{3}$ & 2013 & 487.000 .000 & 549.862 .872 & Naik \\
$\mathbf{4}$ & 2014 & 805.000 .000 & 746.875 .269 & Turun \\
$\mathbf{5}$ & 2015 & 1.681 .078 .927 & 1.700 .057 .510 & Naik \\
\hline
\end{tabular}

Sumber: Dinas Pendapatan Daerah Kabupaten Minahasa Utara, 2017

Berdasarkan Tabel 1.1 dapat dilihat bahwa realisasi penerimaan pajak hotel di Kabupaten Minahasa Utara tahun anggaran 2011-2015. Pada tahun 2011 target pendapatan sebesar Rp 380.000.000,00 dan realisasi sebesar Rp 449. 277.596,00. Pada tahun 2012 target pendapatan sebesar Rp 867.180.000,00 dan realisasi sebesar Rp 593.931.004,00. Pada tahun 2013 target pendapatan sebesar Rp 487.000.000,00 dan realisasi sebesar Rp 549.862.872,00. Pada tahun 2014 target pendapatan sebesar Rp 805.000.000,00 dan realisasi sebesar Rp 746.875. 269,00, dan pada tahun 2015 target penerimaan sebesar Rp 1.681.078.927,00 dan realisasi penerimaan sebesar Rp 1.700.057.510,00.

\subsection{Pembahasan}

\section{Perhitungan Evektifitas Pajak Hotel}

Dari hasil perhitungan efektivitas pajak hotel menujukkan bahwa tingkat efektivitas penerimaan pajak hotel di Kabupaten Minahasa Utara pada tahun 2011 sebesar 118,23\% (sangat efektif) karena realisasi penerimaan pajak hotel melebihi target yang ditetapkan. Pada tahun 2012 tingkat efektivitasnya menurun menjadi sebesar 68,49\% (kurang efektif) karena realisasi penerimaan pajak hotel tidak mencapai target yang ditetapkan. Pada tahun 2013 tingkat efektivitasnya menjadi sebesar $112,91 \%$ (sangat efektif) karena realisasi penerimaan 
pajak hotel melebihi target yang ditetapkan. Pada tahun 2014 tingkat efektivitasnya menjadi sebesar $92,78 \%$ (efektif) karena realisasi penerimaan pajak hotel hampir mencapai target yang ditetapkan, dan pada tahun 2015 tingkat efektivitasnya menjadi sebesar 101,13\% (sangat efektif) karena realisasi penerimaan pajak hotel melebihi target yang ditetapkan.

\section{Perhitungan Kontribusi Pajak Hotel}

Dari hasil perhitungan kontribusi penerimaan Pajak Hotel terhadap PAD Kabupaten Minahasa Utara, dapat diketahui bahwa kontribusi Pajak Hotel terhadap PAD dari tahun 2011-2015 terus berubah-ubah. Pada tahun 2011 kontribusi penerimaan pajak hotel yang diberikan sebesar 8,52\% dari total realisasi anggaran sebesar $\mathrm{Rp}$ 449.277.596. Pada tahun 2012 kontribusi penerimaan pajak hotel yang diberikan sebesar 5,55\% dari total realisasi anggaran sebesar Rp 10.710.695.408. Pada tahun 2013 kontribusi penerimaan pajak hotel yang diberikan sebesar 4,89\% dari total realisasi anggaran sebesar Rp 11. 256.793.033. Pada tahun 2014 kontribusi penerimaan pajak hotel yang diberikan pajak hotel sebesar 3,72\% dari total realisasi anggaran sebesar $\mathrm{Rp}$ 20.070.101.061. dan pada tahun 2015 kontribusi penerimaan pajak hotel yang didiberikan sebesar $6,73 \%$ dari total realisasi anggaran sebesar Rp 25. 266.469.042. Dengan melihat presentase keseluruhan kontribusi pajak hotel pada tahun 2011 sampai dengan tahun 2015 memberikan kontribusi yang sangat kurang terhadap pendapatan asli daerah dengan rata-rata presentase kontribusi per tahun 5,88\% sehingga tidak mempengaruhi jumlah pendapatan asli daerah yang diterima. Pada tahun 2011 sampai 2014 kontribusi pajak hotel terus menurun, namun pada tahun 2015 mengalami kenaikan.

\section{Perhitungan Realisasi Penerimaan Pajak Hotel}

Berdasarkan perhitungan dapat dilihat bahwa realisasi penerimaan pajak hotel terjadi kenaikan sebesar $24,36 \%$ pada tahun 2012, tahun 2013 mengalami penurunan sebesar (8,01\%), pada tahun 2014 mengalami peningkatan sebesar $26,38 \%$ dan pada tahun 2015 mengalami penurunan sebesar 56,07\%. Selanjutnya untuk mengetahui rata-rata tingkat kenaikan potensi pajak hotel dapat dihitung dengan cara menjumlahkan seluruh realisasi potensi dari tahun 2011 sampai dengan 2015 lalu dibagi sesuai dengan tahun anggaran yang diteliti. Kemudian untuk menghitung potensi pajak hotel pada tahun 2016 dapat di lakukan dengan cara menjumlahkan total rata-rata tingkat kenaikan potensi pajak hotel dengan seratus persen, lalu dikalikan dengan total realisasi anggaran pada tahun 2015. Dengan melihat presentase potensi yang diberikan pajak hotel terhadap Pendapatan Asli Daerah Kabupaten Minahasa Utara dapat disimpulkan bahwa kenaikan realisasi potensi tiap tahun selama kurun waktu 2011-2015 sebesar 24,7\% dengan jumlah Rp 2.119.971.714,97, dan dapat kita simpulkan bahwa potensi penerimaan pajak Hotel pada tahun 2016 akan mengalami kenaikan.

\section{KESIMPULAN DAN SARAN}

\subsection{Kesimpulan}

Penelitian ini dimaksudkan untuk mengevaluasi efektivitas, kontribusi dan potensi pajak hotel terhadap pendapatan asli daerah di Kabupaten Minahasa Utara periode anggaran tahun 2011 sampai 2015. Perusahaan perlu meningkatkan profesionalitas pekerjaan dan juga meningkatkan evektifitas, kontribusi dan potensi pajak hotel untuk meningkatkan pendapatan asli daerah.

\subsection{Saran}

Berdasarkan hasil penelitian dan pembahasan yang dilakukan penulis maka sebagai bahan pertimbangan agar tingkat efektivitas, kontribusi dan potensi penerimaan pajak hotel dapat lebih optimal maka diperlukan lagi beberapa penyempurnan atas kekurangan yang ada sebelumnya. Untuk itu penulis mengemukakan saran sebagai berikut: 
1. Dinas Pendapatan Daerah Kabupaten Minahasa Utara bekerja sama dengan Badan Pengelola Keuangan dan Barang Milik Daerah, bidang pariwisata, dan instansi-instansi yang ada diharapkan terus meningkatkan kinerjanya agar profesionalitas pekerjaan terus membaik dan tingkat efektivitas yang sudah baik tetap terus konsisten terlebih bisa meningkat.

2. Untuk target pajak hotel harus ditingkatkan sesuai dengan target pendapatan asli daerah Kabupaten Minahasa Utara agar setiap tahun pajak hotel akan memberikan kontribusi yang terbaik. Untuk meningkatkan kontribusi penerimaanyang bersumber dari pemungutan pajak daerah maka harus dilakukan dengan upaya-upaya sebagai berikut.

a. Meningkatkan efektivitas pemungutan pajak daerah Kabupaten Minahasa Utara.

b.Menggali Potensi dan kebutuhan masyarakat didaerah dan sekaligus memberikan jenis-jenis pelayanan publik yang dibutuhkan oleh masyarakat di daerah, dengan demikian akan terjadi peningkatan penerimaan pajak.

c. Mengembangkan objek-objek wisata beserta infrastrukturnya agar menarik banyak turis lokal maupun asing untuk mengunjungi Kabupaten Minahasa Utara, sehingga kontribusi penerimaan pajak hotel semakin meningkat.

Melakukan sosialisasi untuk memberikan arahan dan bimbingan kepada wajib pajak baru dalam melakukan sosialisasi untuk meningkatkan kesadaran masyarakat dalam membayar pajak.

\section{DAFTAR PUSTAKA}

Francis Pol C. Lim, (2013), Impact Of Information Technology on Accounting Systems. AsiaPacific Journal of Multimedia Services Convergent with Art, Humanities and Sociology Vol. 3 (2):93-16

Lamia, Alfan, (2015), Analisis Efektifitas dan Kontribusi Pemungutan Pajak Restoran, Pajak Reklame, dan Pajak Penerangan Jalan Pada Pendapatan Asli Daerah Kabupaten Minahasa Utara. Jurnal EMBA: Fakultas Ekonomi dan Bisnis, Universitas Sam Ratulangi, Manado.

Sondakh Jullie, Ibrahim Driyana \&Wangkar Aneke. 2016. Analisis Perbandingan Potensi Penerimaan dan Efektivitas Pajak Penerangan Jalan Kabupaten Minahasa Tenggara. Fakultas Ekonomi dan Bisnis, Universitas Sam Ratulangi, Manado.

Sugiyono. 2011. Metode Penelitian Pendidikan. Bandung, Alfabeta

Khotimah, Qusnul (2014), Analisis Potensi dan Efektivitas Penerimaan Pajak Hotel dalam Meningkatkan Pendapatan Asli Daerah. Fakultas Ekonomi dan Bisnis, Universitas Brawijaya, Malang.

Kobandaha, Rezlyanti (2016), Analisis Efektivitas, Kontribusi dan Potensi Pajak Reklame dan Pajak Hotel Terhadap Pendapatan Asli Daerah Kota Kotamobagu. Jurnal EMBA : Fakultas Ekonomi dan Bisnis, Universitas Sam Ratulangi.

Lamia, Alfan, (2015), Analisis Efektifitas dan Kontribusi Pemungutan Pajak Restoran, Pajak Reklame, dan Pajak Penerangan Jalan Pada Pendapatan Asli Daerah Kabupaten Minahasa Utara. Jurnal EMBA: Fakultas Ekonomi dan Bisnis, Universitas Sam Ratulangi, Manado.

Toding, Ronald Bua (2016), Analisis Potensi dan Efektivitas Pemungutan Pajak Hotel dalam Meningkatkan Pendapatan Asli Daerah Kota Palangka Raya. Jurnal EMBA: Fakultas Ekonomi dan Bisnis, Universitas Sam Ratulangi, Manado.

Waluyo. 2011. Perpajakan Indonesia. Jakarta : Salemba Empat 